\title{
Supplier-Buyer Collaboration Versus Productivity
}

\author{
Bernard F. Monnaie ${ }^{1}$ \\ ${ }^{1}$ University of Seychelles, Seychelles \\ Correspondence: Bernard F. Monnaie, University of Seychelles, Seychelles. E-mail: bfmonnaie@gmail.com
}

Received: November 26, 2016

Accepted: January 3, $2017 \quad$ Online Published: March 30, 2017

doi:10.5539/jsd.v10n2p83

URL: https://doi.org/10.5539/jsd.v10n2p83

\begin{abstract}
Firms that upgrade and then maintain supply-demand matching collaboration with a highly-governed commercial chain, like a Global Value Chain (GVC), are thought to obtain better opportunities for improving their business prospects. This paper reviews a study on such a hypothetical impact by using data from the fish value chain of Seychelles, comprising a few small-scale producers that have upgraded to supply foreign markets. The difference in the mean value of 5 months' of production capacity, actual output and productivity (as total output value/input value) of random fish suppliers that had upgraded $(n=34)$ and not upgraded $(n=32)$ were tested. Four of the upgraded suppliers were subsequently interviewed on key production-related attributes. Only the difference in the mean productivity figures of the two groups of firms was not significant. The interviews suggest that (1) the productivity of upgraded suppliers is strongly impacted by their directly-controlled resources and exploited fish stocks and (2) viability challenges motivate upgraded suppliers to multi-chain and target various foreign and native customers. The results indicate that supply-demand collaboration in a highly-governed fish chain allows small-scale producers to improve their production capacity, associated output and their potential productivity too if it helps strengthen the environmental sustainability of their fish stocks.
\end{abstract}

Keywords: upgrading, value chain, productivity, environmental sustainability, SMEs

\section{Introduction}

Two hypotheses often found in the GVC literature (Van Dijk, 2012; Humphrey and Schmitz, 2001; Gereffi, 2001), for instance: (1) firms that upgrade to participate in a GVC improve their business prospects and (2) governance positively impacts on the business prospects and processes of an upgraded firm. Empirical tests of such hypothetical impacts have not been traced in the small-scale fishing industry but in various others, including the apparel \& car manufacturing (Gereffi, 2001, for example) and agri-food (Lee et al., 2010, for example). However, it's worth noting that FAO (2010) estimates that most fishers are small-scale, artisanal fishers, operating on coastal and inland fishery resources. Delgado et al. (2003) further add that the net annual fish exports from developing to developed countries is around US\$15 billion and surpasses the monetary value of many other traditional developing-country agricultural exports. A sectorial review of the fishing industry of Seychelles revealed that the country has among the top 10 world per capita fish consumption, around $60 \mathrm{~kg}$. The industry also has a well-developed, foreign-dominated, export-oriented industrial tuna value chain and a developing fresh and frozen fish (FFF) value chain, which is reserved for domestic harvesters targeting common-pool fish stocks on an open-access basis. In the FFF chain, an average of 72 percent of fish harvesters operate vessels with smaller production capacities. The balance of around 32 percent of larger-capacity harvesters produce around 61 percent of the chain's total production. In addition, about 11 percent of the larger-capacity operatives do not only collaborate with traders targeting primarily foreign consumers - including the fish plants, domestic distributors, hotels and tourist establishments, but also have more sophisticated production systems and set up their base nearby the fish plants. Moreover, the FFF chain is awarded a variety of subsidies to its capital and variable costs, namely below-market loans, taxes, fuel and ice; sickness benefits; free-of-charge port facilities as well as monitoring and surveillance services. Curiously, in spite of its gradually increasing demand and production subsidies, the output of the FFF chain started an unsteadily decreasing trend after peaking in late 1980s, just a few years into initiatives for industrializing its production. Nevertheless, in interviews, the CEOs of targeted institutional buyers reveal that their ties with the larger-capacity operatives do apply a downward pressure on their supply risk. Drawing on the works of Van Dijk (2012), Humphrey and Schmitz (2001) and Gereffi (2001) and other developmental scholars, the dynamics of the FFF chain suggested that it is a potentially rich source of data for empirically testing the impact of 'upgrading' on lower-tier 
small-scale producers. In particular, although 'upgrading' appears to be the mechanism that helps the few larger-capacity operatives to collaborate with the institutional buyers - for supply-demand matching purposes its associated high-intensity exploitation appears to also impact the overall declining production trend of the chain. This paper analyses such potential paradoxical impacts of upgrading and its associated supplier-buyer collaboration on the productivity of small-scale fish producers. First, it reviews the conceptual discussion on upgrading and supplier-buyer ties as development mechanisms. A mixed-method study of upgrading and supplier-buyer ties on the production capacity, output and productivity of suppliers of institutional buyers is subsequently analysed.

\section{Conceptual Framework}

A model of development that appears to be gathering traction draws on the value chain concept. This concept, among other things, views every business as being a participant of an deliberate consumer value creation process and that a particular product or service realizes its inherent 'consumer value' only when it's purchased. Now, in many instances, especially in cross-border trades, there are a number of independent businesses involved in realizing a particular product/service for a target group. Each of these businesses adds a charge for their involvement that more vividly shows up in the rising monetary value/cost of a product/service - as it crosses each one of them - on the way to the final customer or consumer. Such a sequence of consumer value adding operations has been collectively described as a value chain - or a GVC, if it crosses borders. Collaboration among them is thought to not only facilitate the underlying consumer value creation process but also improve the benefits of all participants and consumers alike. In this sense, inter-firm ties helps to regulate the value-creation process for increasing not only consumer value (or benefits package), but also individual and collective productivities in a chain. Simatupang (2007) defines chain collaboration as a means for two or more companies to establish joint efforts in identifying and delivering products to end customers that lead to better revenues and lower costs. Drawing on the views of DiMaggio and Powell (1983), respectively, such ties are likely to facilitate diffusion of successful practices among chain participants - through the process of 'normative isomorphism' or benchmarking. In this sense, firms are assumed to be passive objects of external forces and adopt external dominant structures/patterns.

Such intra-chain regulation may focus on different aspects of a particular value-creation process depending on different factors, including the nature of the chain and its participants, the type of raw material resources that are exploited, the market and the institutional environment - framework of assumptions, values, laws, rules, norms and other factors governing human behaviour. For instance, Simatupang (2007), contend that general practices include information sharing systems, collaborative business processes, collaborative incentive schemes and collaborative performance systems. Lee et al. (2010) add that transnational agri-food chains systemically integrate small growers in developing countries as a way of increasing their flexibility to source high-volume, low-price diversified products on a year-round basis. Bourlakis et al. (2004) further contend that an increasing consumer demand for convenience pressures the food industry to inter alia cut lead time and deliver on-time to meet consumer needs better, faster and at less cost and that co-ordinating product flows may improve cost and service.

The leadership of inter-firm collaboration is believed to be crucial for any serious consumer value improvement and associated chain competitiveness. It tends to be provided by a so-called 'lead firm', which is mostly based in the developed world. In producer-driven chains - as Gereffi (1994) contends, the key parameters are set by firms which control key product and process technologies as in the car industry, for example. In buyer-driven chains the key parameters are set by retailers and brand-name firms which focus on design and marketing, not necessarily possessing any production facilities. Contributing to the debate, Humphrey and Schmitz (2001) contend that the trade in labour-intensive products is increasingly organised by global buyers, who may work for, or act on behalf of, major retailers or brand-name companies. Lee et al. (2010) add that in agri-food producer-driven chains, the responsibility for potential safety failures lies with the processor in developing countries who impose requirements on farming activities. Further still, Humphrey and Schmitz (2001) argue that lead firms urge cost reduction; quality and speed improvements; transmit best practices; help improve layout, production flows and skills. Such high challenge and support found in highly governed chains potentially explain how relatively underdeveloped regions quickly become major export producers. However, Kaplinsky (2000) argues that standards can also be set by parties outside a chain, including regulatory authorities. Indeed, in different countries there are not only varying regulations but also different government agencies and self-help organizations that help oversee multiple aspects of business operations, including health \& safety, employment practices, environmental protection and conservation. By implication, participants of a value chain, and particularly a GVC, are likely to be subjected to a variety and potentially conflicting 'governance instruments', 
which simplistically are schemes for focussing businesses on the interest of their shareholders. For instance, in the case of the nutritionally and commercially important fish GVCs, such schemes include international agreements - like on fishing grounds and quotas, commercial standards - such as production quality and quantity parameters set by lead firms, and national regulations - including production subsidization, surveillance and control. In this perspective, governance helps integrate a chain, streamlining its operations for inter alia increasing individual and collective efficiencies. It is also often used to generalize differences in value chains. For example, a typology of value chains commonly found in the GVC literature is the one proposed by Schmitz (2004) who contends that enterprises may (1) deal with each other in arm's length transactions (2) co-operate and have complementary competences without control over each other; (3) engage in captive or quasi-hierarchical relationships in the case when the lead firm of a chain sets parameters under which others operate; (4) participate in a hierarchy if they are vertically integrated as in the case when a parent company controls its subsidiaries. However, this paper uses a dichotomous typology of value chains. Those chains whose participants deliberately cooperate for improving business gains and consumer value are assumed to be Managed Value chains (MVC) and by contrast, those chains in which participants do not display similar intentional cooperation are identified as Open-market Value Chains (OVC).

A mechanism thought to help a small firm to link up with a highly governed chain is upgrading. As the above conceptual discussion suggests, a governed/managed value chain, harbours multiple barriers of entry that tend to be strongly related to cost, quality and quantity of production. In the views of Barney \& Hesterly (1999) a chain may create such barriers as part of its strategy for boosting concentration in the relevant economic sector and, with it, competitive advantage. Consequently, a firm wishing to improve its business prospects by thrusting into such a chain has no alternative but to overcome its inherent entry barriers. Doing so may be quite challenging for a small firm - which tends to have a relatively weak resource base. In the words of Harper (1984) the developing-country small enterprise, in particular, serves the poor who do not only limit its market but also inclines it towards small-scale, labour-intensive, flexible and locally-made equipment. In order to overcome the basic entry barriers of a highly governed chain, such an enterprise needs to upgrade its production process by at least upscaling and raising the standard of its production. These adjustments assumedly allow the enterprise to improve its productivity through economies of scale. As Van Dijk and Trienekens (2012) contend, upgrading in most cases requires attention for multiple business aspects. Depending on its focus and nature, it is labelled differently: product, process, functional upgrading. Product upgrading allows a firm to produce a higher value-added product. Process upgrading helps a firm to rationalize its production system and boost its productivity. Finally, functional upgrading enables a firm to carry out untried functions, like those involving the transformation of some properties of raw materials - fish canning, for example. Van Dijk and Trienekens (2012) add that in developing-country value chains, product and process upgrading are most common; functional (value-added) and inter-sectoral upgrading occur less as the producers involved are still commodity suppliers for their Western value chain partners.

In sum, the value chain concept calls for the orientation of business activities to customers, with the view of improving customer value - or benefits package. A business that espouses the concept is naturally drawn to collaborate with others in the underlying consumer value creation process. Collaboration in highly-governed and, usually higher-returns, chains is mostly lead by a developed-country firm that sets governing parameters, which all participants comply with and thus tantamount to entry barriers. Upgrading is thought to be a mechanism that enables a small producer to overcome the entry barriers of a governed chain, improve its productivity and overall business outlook.

\section{Methodology}

The above conceptual framework readily suggests that an empirical test of the impact of upgrading on a small producer calls for not only a comparison of the business outcomes of those producers that upgrade and those that do not but also the apportioning of such outcomes among factors relating directly to participation in a managed value chain (MVC) and those associated with the firm proper. Hence, the test readily lends itself to a mixed-methods investigation. The quantitative phase of the study under review was guided by three hypotheses that were motivated by characteristic attributes and behaviours of FFF value chain suppliers. In particular, the lower-capacity harvesters do not only dominate the chain but they also tend to be day-trip suppliers of fresh whole fish to native, road-side customers - typically, on their way from work. The larger-capacity harvesters tend to be multi-day suppliers of rudimentarily-treated and cold-stored whole fish to institutional buyers, including fish plants, hotels, restaurant and other businesses that target predominantly foreign consumers - as local visitors or mostly in Europe. Such traders tend to individually manage their fish supply - routinely securing a higher quantity and quality of harvest. By contrast, the customers of lower-capacity harvesters tend to buy a 
much lower quantity of fresh whole fish. On this basis, while larger-capacity harvesters tend to target MVC buyers, those with lower production capacities tend to trade with OVC customers.

Another important production-related attribute of all FFF value chain suppliers is that they are incentivized to fish at will and de facto not obliged to record their production data, let alone surrender them to the authorities. Instead, their landings are daily evaluated by government field enumerators.

The first hypothesis that the above discussion motivated is that MVC suppliers are likely to have higher outputs than their counterparts outside the chain, in the OVC. The visible difference in the vessel size used by MVC and OVC suppliers motivated a second hypothesis, namely, that MVC suppliers are likely to have higher production capacities than their OVC counterparts. Further still, the high perishability rate of fresh whole fish and the relatively limited sale period of OVC suppliers - typically from around noon till around 18:00hrs, seemingly pressure the OVC suppliers to not only restrict how much they produce but also when to start and stop doing so. Indeed, if an OVC supplier lands a particular harvest past its peak sale period, its viability is seriously jeopardized. By contrast, as the MVC suppliers are multi-day operations and cold-store their catch, their harvesting and landing operations are not as time-bound as their OVC counterparts. In fact, they may even negotiate their landing times with their institutional buyers and thus keep harvesting up to their optimum production capacity. Such dissimilar production objectives of MVC and OVC firms compellingly pointed to yet another potentially crucial difference between them, namely, in their unused production capacities. As a corollary, the associated third testable hypothesis is that MVC suppliers are likely to have higher individual productivities than their OVC counterparts. The qualitative part of the study helped apportion these three hypothesized quantitative impacts among their potential sources. Two assumptions helped keep the study focussed on production-related attributes: the fish MVC is an attractive market for (1) already higher producing small-scale suppliers (2) small-scale suppliers with higher production potential.

\subsection{Study Phases and Participants}

The first part of the study was a face-to-face screening survey of a sample of independent fish suppliers from the MVC and OVC, separately. In the case of the MVC, both the suppliers and their respective buyers were interviewed. For this survey, 50 suppliers of the two domestic fish plants - local GVC intermediaries, were purposively selected and mixed in a long-list with another 50 randomly-selected suppliers from a database of licensed fishing firms. In total, 70 randomly-selected fishing firms (36 from the MVC and 34 from the OVC) accepted to participate in the study. They were subsequently individually interviewed - with confidentiality assurance, on six categorical variables, namely, their harvest disposal - whether/not for sale, harvest landing site, production capacity, point of sale, main buyer, and supplier-buyer link type. If a firm reported harvest-to-order ties with its typical buyers, it was assigned to the MVC, and if not, to the OVC. The second phase of the study was weighing of fish landings of the shortlisted firms over 5 months during their peak fishing season, November 2013 through March 2014. The third part of the study involved semi-structured interviews of four of the participating MVC firms with the highest recorded absolute outputs.

\subsection{Procedures}

Descriptive analysis was performed on the survey dataset to sort the 70 interviewed participants into the conceptualized MVC and OVC groups of suppliers. The main approach for evaluating the landings of the OVC firms was the weighing of a sample of individual landed species and subsequent multiplication by the total quantity of each respective specimen. The enumeration was conducted six days a week by trained government field enumerators equipped with a hand-held spring-balance scale of $25 \mathrm{~kg}$ capacity. Landings of the MVC firms were weighed by their institutional buyers - with the aid of digital scales with a capacity of up to $3,000 \mathrm{~kg}$.

The quantitative dataset was first cleaned from zero returns. Also, shortly after the end of the five-month period of observation, a participating firm lost its vessel and crew at sea. For purely ethical reasons, data collected from that firm were eliminated. The data cleaning process shrunk the independent samples to $34 \mathrm{MVC}$ and $32 \mathrm{OVC}$ firms. Table 1 summarises key characteristics of those firms. As shown, MVC suppliers tend to trade with the local fish plants. OVC fishers typically dispose of their produce primarily to the general public. The average production capacity of the few MVC firms that target various buyers outstrips that of those trading with the fish plants. Similarly, in the OVC, firms that sell their produce to fish traders have an average fish-hold, which far exceeds that of firms trading with the public. 
Table 1. Key attributes of studied fishing firms

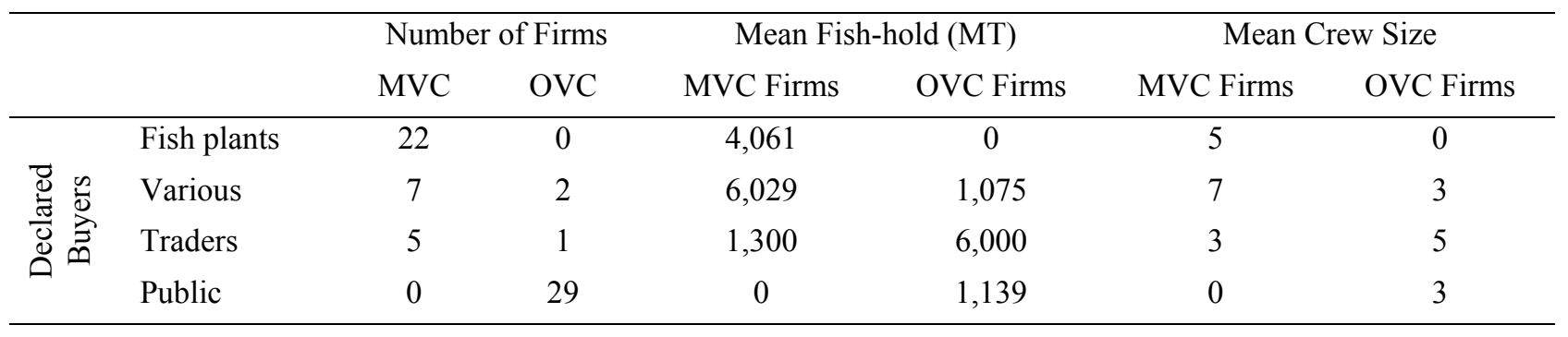

Descriptive analysis was performed on the shrunk dataset to select four MVC firms with the highest absolute outputs for the in-depth qualitative part of the study, i.e., the semi-structured interviews. The number of landed harvests provided the number of fishing trips or production runs undertaken by each firm. This number was multiplied by their fish-holding/production capacity to provide the total production capacity in kilograms that was available to each of them during the 5-month data collection period. The actual total harvest in kilograms was deducted from the total available production capacity to provide the unused production capacity or productivity of each firm. Unequal variances t-tests were then performed on the means of the actual output, production capacity and productivity levels of the MVC and OVC firms. The semi-structured interviews were conducted in July \& September 2014 in the native language of the owners of the supplying firms under observation and recorded by the author of this paper. Informed consent in writing was obtained from those owners and confidentiality assurance was provided to them. Transcription and translation to English of three sets of the recordings were undertaken by professional translators and, owing to their subsequent unavailability, one set was transcribed and translated by the author. Exclusive and unifying heterogeneous attributes of each firm were extracted from the transcripts with the aid of the content analysis technique, described by Krippendorff (2004).

\section{Results}

\subsection{Survey}

The bases of all FFF value chain suppliers tend to be close to their principal buyers. While MVC suppliers are based nearby institutional buyers, OVC suppliers are found mostly in suburban and rural communities. In respect of their main customers, MVC suppliers tend to sell $79 \%$ of their landings to the processing-exporting plants and the balance (21\%) to multiple MVC \& OVC buyers. By contrast, OVC firms sell $91 \%$ of their fish to price-sensitive customers and the balance $9 \%$ to multiple MVC \& OVC buyers. In addition, $85 \%$ of MVC suppliers maintain supply-demand ties with their institutional buyers, albeit more strongly with the fish plants. The balance, $15 \%$ of the MVC suppliers, appears to trade with the fish plants without pre-set terms \& conditions. While $32 \%$ of MVC suppliers had not less than six crew members, $91 \%$ of OVC suppliers had under 6 crew members, although crew variability assumedly occurred in both cases. About their production capacity, $56 \%$ of MVC suppliers could carry in excess of $3 \mathrm{~T}$ of fish per fishing trip, and close to $9 \%$ of them could produce and land between $12 \mathrm{~T}$ and around $16.5 \mathrm{~T}$ of fish. However, $88 \%$ of OVC suppliers, could harvest and land less than $3 \mathrm{~T}$ of fish per production run and only $3 \%$ could carry at least 9T of fish.

\subsection{Quantitative Analysis}

Over the five months of observation, OVC suppliers undertook an average of 20 production runs or about twice more than the 9 average trips of MVC suppliers. Interestingly, the average fish harvest of the OVC suppliers of around 1.7T was about 4 times less than for MVC harvesters of 6.6T. Curiously, far more MVC than OVC harvesters underutilized their production capacity. For example, 167\% more MVC than OVC suppliers did not use between $10 \& 15.5 \mathrm{~T}$ of their aggregate production capacity. And 100\% more MVC than OVC suppliers did not produce between $15.9 \& 25 \mathrm{~T}$ of mean potential harvest. Lastly, around 18\% of MVC harvesters wasted 63T of their aggregate production capacity.

An independent samples t-test was subsequently undertaken to assess the statistical significance of each of the three research hypotheses, namely, a positive difference in the means of the actual harvest, production capacity and productivity figures of MVC $(n=34)$ and OVC $(n=32)$ suppliers. The normality assumption of the $t$-test was assessed and satisfied by the D'Agostino-Pearson test for normal distribution. As the samples came from log-normal distributions, they passed the test in logarithmic scale (at skewness $=0.36 \& 0.86$, kurtosis $=0.69 \&$ $0.79, p$-value $=0.39 \& 0.07$ for the MVC \& OVC distributions, respectively). Additionally, the t-test assumption 
of homogeneity of variances for all three distributions was tested and satisfied by Levene's F-test for equal variances (at $p<0.01$ in all three cases).

The t-tests generated a $\mathrm{p}<0.01$ for the difference of means in the output and production capacity data but a $\mathrm{p}=$ 0.14 on the unused production capacity figures. Thus, the samples provide overwhelming evidence in favour of the research prediction of a clear difference in the mean outputs and production capacities of the two groups of suppliers but confirmed that the difference in the means of their unused production capacities or productivities is not statistically significant, at 0.05 level.

\subsection{Analysis of Semi-Structured Interviews}

The owners of the upgraded suppliers share over $80 \%$ of the 11 discerned patterns of personal attributes. In particular, all the owners fall in the 'active age' range of 20-50 years; transferred managerial expertise from another one of their businesses predominantly in different economic sectors; have a higher profit ambition; are dedicated to their fishing firm; have access to multiple sources of finance; were inspired to enter the MVC by its seasoned operatives and reportedly feel a sense of responsibility for maintaining fish supplies for native customers. However, $50 \%$ of the owners share ownership of their MVC fishing business with a blood sibling and $75 \%$ of them considered their fishing business as important and aimed to further upscale production.

All MVC suppliers are based nearby their primary institutional buyers; respond to business threats - in this case, shifts in demand \& fish stocks; engage in vertical collaboration; have multiple finance sources; pay their staff on a piece-rate basis and proactively manage their wastage risks. However, only $75 \%$ of the suppliers target exclusively high-yielding markets and service a loan. Lastly, only $50 \%$ of the upgraded harvesters are over five years old and have family origins.

Additionally, all the interviewed MVC suppliers experience seasonal production variability; target multiple species and undertake basic post-harvest preservation. The suppliers also share the same staff characteristics. Their sole skipper seemingly serves as their operations and often sales managers. Their staff tend to be unskilled, live off fishing, regularly change jobs and, as perhaps a consequence, are casually employed and trained mostly on the job.

Finally, there is an apparent variability in fish capture characteristics among the MVC suppliers. All of them use selective fishing gears. However, $75 \%$ of them enjoy in excess of $3.9 \mathrm{~T}$ of average production capacity and target multiple - albeit offshore fishing grounds, hence requiring longer-haul batch production runs. But only $50 \%$ of them reportedly use some modern harvesting technologies.

\section{Discussion}

The quantitative part of the study statistically supports the predicted positive impact of supplier-buyer collaboration and its associated upgrading on the output and production potential but not the productivity of small-scale producers. Both the survey and in-depth interviews help to shed light on a seemingly insightful narrative of this result.

Drawing on the findings of the survey and in-depth interviews, an MVC supplier tends to use a more sophisticated production technology and operate from a vessel having a higher production capacity - averaging three times more than for an OVC supplier. Revealingly, the MVC supplier acquires such higher production facilities on upgrading its production process by leveraging an array of its internal but also external expansion resources. Those resources are its higher profit ambition plus access to multiple growth finance sources - both internal and external, access to offshore biological resources and access to higher-returns MVC customers. The profit ambition of the MVC supplier inclines it to diversify into export-oriented fishing from another one of its businesses in a different economic sector. Through various media, the supplier obtains intelligence on MVC demand and related business opportunities from seasoned suppliers of the processing-exporting plants. Using its own and external growth finance, the MVC supplier then acquires a fishing vessel that is able to undertake longer-haul fishing trips to harvest the typical offshore, and higher quantity fish demand of a fish plant, its main buyer. Among other things, the MVC supplier comes under competitive pressures to strengthen ties with the fish plants, selling the bulk of its harvest to them and even relocating its base of operation closer to theirs. Hence, a MVC supplier tends to have a higher production potential, thus supporting the second assumption of the qualitative part of the study. This potential subsequently increases the supplier's opportunities for higher outputs - as the result of the differences in the mean production capacity and output compellingly reflect.

However, the exploited biological resources of the MVC supplier are not only offshore but also highly perishable, deep sea, seasonal and elusive - being inter alia wild, sensitive to time of exploitation \& weather conditions, and also require some post-harvest preservation, including cold storage. Indeed, assuming a harvester uses the right 
exploitation technique then its output is likely to be better not only in calmer than in rough weather but also at some times of the day/month/year than at others. In addition, the productivity of commercial fauna is inter alia subject to not only the aggregate exploitation intensity but also environmental variability. Undoubtedly, the higher outputs of MVC suppliers already indicate a relatively high aggregate exploitation intensity. And, apart from its widely-accepted adverse impacts on global temperature and allied climate variability, global pollution is being increasingly linked with perturbation in the temperature, chemistry and current patterns of the habitats of key targeted marine resources. Set against the inaccessibility of some resources - owing to the closure of fishing grounds threatened by Somalian Pirates, such potential impacts of global pollution compellingly suggest that the productivity of the resources targeted by the MVC suppliers does not only tend to vary with/in each fishing trip, but is also under a declining pressure.

On the basis of these processes, the upgraded harvester faces highly volatile production conditions. Its every production run faces a high risk of missing its objectives and associated losses. Such challenges suggest that, at best, the supplier has a high likelihood of not totally fulfilling the supply orders of its key buyers - in this case, the processing-exporting plants, and, at worse, returning to base empty-handed - thus wasting its whole production capacity. Hence, the harvester's baseline wastage risks or inefficiency risk factors are potentially significant. Associated viability pressures motivate it to iteratively adjust its every production run. Evidentially supporting such inference, the upgraded supplier tends to routinely divert its likely fish-plant rejects to other buyers and attempts to maximize the use of its potential unused fish-hold by harvesting some species for sale to primarily lower-income OVC customers. As it turns out, most MVC suppliers have two branches of operations: for targeting the plants and OVC customers, respectively. Moreover, the inefficiency risk factors of the upgraded harvesters seem to incline the fish plants to partially multi-source supply. As the harvesters with whom the plants collaborate tend to be unable to consistently fulfil negotiated supply orders, the MVC buyers resort to sourcing some supply on a first-come first served basis from any available upgraded harvester. The earlier cited $15 \%$ fish sales to MVC buyers without pre-set terms \& conditions most probably make visible the extent of such multi-sourcing processes in the chain. By implication, there is a fair level of indeterminacy in the vertical (supplier-buyer) ties in MVC. Although the antecedent of such indeterminacy is unclear, the supplier cannot guarantee fulfilment of an order and the buyer cannot guarantee purchase of the whole delivery of its contract harvester. And further compounding its operational challenges, an MVC supplier tends to delegate practically its whole production management to a technician - the skipper/captain. In addition, most of the supplier's fishing hands tend to be unskilled, on-the-job trainees and casual workers who cyclically move around the FFF value chain. Drawing on the arguments of Slack et al. (2013), the manner in which an organization's human resources are managed has a profound impact on the effectiveness of its operations function. As most human resources are found in operations, the ones most involved in their leadership, development and organization are operations managers. By implication, the discussed production-related behaviours of the fishing hands do not only reflect their own individual knowledge, skills and attitudes base but those of the skipper-manager too.

What such dynamics compellingly suggest is that the upgraded supplier has important productivity risks at its key stages of operation, namely, input, transformation and output. Among other things, its human resources are relatively weak, particularly, in business leadership and production skills. Its core transformation operation exploits resources whose productivity is volatile and indicatively declining. Lastly, at its output stage of operation, the MVC demand that it targets is not only quasi-independent but also relatively uncertain. As a way of managing such routine business risks for keeping up its viability, the upgraded supplier of the MVC opportunistically multi-chains, harvesting species for multiple MVC and OVC buyers. As such, the MVC supplier pursues a combination of 'production scale' and 'production scope' upgrading. Whereas through production scale upgrading it increases its output volume, production scope upgrading enables it to increase its output variety by exploiting species for both MVC \& OVC customers. Such behaviours make visible what appears to be characteristic upgrading processes that small suppliers of the reviewed FFF value chain adopt for linking up with the MVC and OVC either occasionally or on a more permanent basis. They are (a) intra-chain production scale upgrading, whereby the firm acquires a new production system to increase the production volume for its existing market (MVC or OVC); (b) cross-chain production scope upgrading, whereby the firm modifies its existing production system to increase its product range for targeting different markets (MVC and OVC) and (c) cross-chain production scale upgrading, whereby the firm acquires a new production system to increase the production volume for its different markets (MVC and OVC).

Such processes readily suggest that the above-described routine inefficiency risk factors do not only have a strong bearing on the productivity of the upgraded supplier but potentially explain why the gathered evidence has failed to support the third research hypothesis of a positive impact of vertical ties on the productivity of small 
upgraded suppliers. Those risk factors arguably stifle MVC demand fulfilment and thus undermine the very purpose of vertical ties. As a result, instead of being 'pulled' on demand by buyers, fish production is 'pushed' by viability pressures of suppliers. This compelling inference aptly brings to light the chain's de facto producer-driven nature. By implication, opportunities for increased individual and collective productivities in the chain context are likely to improve if in addition to expanding the exploitation technology of suppliers, governance also improves the productivity of both their human and exploited marine resources.

\section{Conclusion}

The GVC conceptual lens argues that governance - including vertical collaboration, national policies and their executive instruments - is the glue that helps sustain a potentially successful chain. In the seafood chain in context, governance - particularly vertical ties, appears to have a predominantly structural/homogenous impact on the small producers. Gathered evidence suggests that by using the existing governance structures, the producers gain access to information, external growth finance and higher-returns markets that in turn help them to upgrade their production process. However, the focus of such upgrading is mostly on production scale \& technology and allied higher output potential. As a result, the producers acquire a production system that, in principle, is optimized for supplying MVC buyers. Hence, the small producers are under competitive pressures to remain 'glued' or collaborate with their buyers through contractual harvest-to-order arrangements.

Thus, on the platform of other governance structures, vertical collaboration creates an exclusive business environment, which is dominated by MVC buyers and their small producers. That business environment is inter alia characterized by higher production capacities, outputs and potential returns but suboptimal efficiency gains of the producers. As such, vertical collaboration enables the buyers to increase their opportunities for managing both their supply risks and the production potential of their small suppliers. In other words, it is the collaboration between suppliers and buyers that essentially establishes the MVC. However, in the case in point, such collaboration fails to provide the small producers consistent access to dependent demand (or firm orders) and to help sustain the productivity of both their human and marine resources. Hence, as the small MVC producers far outnumber their principal buyers, the distribution of vertical collaboration gains is skewed in favour of the buyers, the fish plants, engaging in more sophisticated and higher-yielding value addition.

In the circumstances, set against the views of North (1994), the results of the qualitative part of the study suggest that the productivity of the human \& marine resources of the small producers is potentially influenced in a significant way by governance instruments outside the FFF chain, (or the wider institutional environment), including wide-ranging subsidies, marine resources management and other policies. As the seafood chain context is predominantly export-oriented to European Union (EU) markets, the said 'environment' is also impacted by international pressures, the EU and other international governing bodies, for example. Those pressures arguably help 'incentivize' the apparent challenges of FFF value chain production linked with not only its human resources of but also with the state of its key marine resources - particularly, their indicative overexploitation and associated declining productivity. In this sense, governance instruments outside the chain appear to be some of, if not, the most important inefficiency risk factors of the upgraded producers. As it tends to face both a relatively volatile production and MVC sales environments, the upgraded supplier opts for a multi-chain business strategy - by targeting both MVC and OVC markets. In order to pursue such a strategy it has few alternatives but to partially downgrade its production process. However, such downgrading does not only help shed light on the relatively strong influence of the OVC demand on the whole FFF chain but, as already discussed above, is also motivated by pressures outside the chain for increasing the exploitation intensity of key resources. As such, governance mechanisms outside the chain help undermine the inherent supply-demand matching objective of vertical collaboration, spearheaded by the lead firm, and this effect alone readily indicates that a small commodity producer of an MVC is more than a homogenous impact of the chain - as a hypothesis often found in the GVC literature predicts. It is also a heterogeneous impact of the wider institutional environment - as the resource-based view of the firm argues.

In the final analysis, when entering the MVC context a small producer undertakes partial production scale and scope upgrading. While scale upgrading allows it to increase its production volume and benefit from economies of scale, scope upgrading allows it to opportunistically multi-chain and target both MVC and OVC buyers and thus reap economies of scope benefits. As this study suggests, the consequences of such processes include weak vertical collaboration as well as suboptimal individual and collective gains in the chain context. Turned on its head, a seafood chain stands to improve its business prospects by enhancing both its vertical collaboration and the environmental sustainability of its exploited fauna. 


\section{Acknowledgements}

The author expresses wholehearted gratitude to the Seychelles Fishing Authority, particularly its CEO, field enumerators and their supervisor, for logistically supporting the research on which this paper draws. In addition, the Judiciary of Seychelles is also thanked for facilitating the third phase of the research, namely, in transcribing and translating 3 of the undertaken interviews.

\section{References}

Barney, J. B., \& Hesterly, W. (1999). Organizational Economics: Understanding the Relationship between Organizations and Economic Analysis. In S. R. Clegg, \& C. Hardy (Eds.), Studying Organization Theory \& Method (pp. 109-141). London: SAGE Publications. https://doi.org/10.4135/9781446218556.n4

CBS. (2007). Annual Report 2007. Seychelles: Author.

DiMaggio, P. J., \& Powell, W. W. (1983). The Iron Cage Revisited: Institutional Isomorphism and Collective Rationality in Organizational Fields. American Sociological Review. Vol. 48, Issue 2, 147-160. https://doi.org/10.2307/2095101

FAO. (2010). State of world fisheries and aquacutlure. Retrieved from: http://www.fao.org/docrep/013/i1820e/11820e00.htm.

FAO. (2014). State of world fisheries and aquaculture. Retrieved from: http://www.fao.org/3/a-i3720e/index.html.

FAO. (2016). FAO Yearbook 2014: fishery and aquaculture statistics. Retrieved from: https://webcache.googleusercontent.com/search?q=cache:1 bvxMAmiwOoJ:www.fao.org/fishery/publicatio ns/yearbooks/en $+\& \mathrm{~cd}=1 \& \mathrm{hl}=\mathrm{en} \& \mathrm{ct}=\mathrm{clnk}$.

Gereffi, G. (2001). Beyond the Producer-driven/Buyer-driven dichotomy: The Evolution of Global Value Chains in the Internet Era. IDS Bulletin, Vol. 32, No. 3

Gutierrez, N. L. (2015). To conduct a risk assessment to identify threats to demersal stocks and stock assessments for key demersal stocks. Seychelles: Seychelles Fishing Authority.

Harper, M. (1984). Small Business in the Third World. Chichester: John Wiley \& Sons.

Humphrey, J., \& Schmitz, H. (2001). Governance in global value chains. IDS Bulletin, 32.3.

Kaplinsky, R. (2000). Globalisation and Unequalisation: What can be learned from value chain analysis? Journal of Development Studies, 37, 2. http://siteresources.worldbank.org/INTAFRSUMESSD/Resources/1729402-1150389437293/Kaplinsky_Va lue_Chain.pdf.

Lee, J., Gereffi, G., \& Beauvais, J. (2012). Global value chains and agrifood standards: challenges and possibilities for smallholders in developing countries. Proceedings of the National Academy of Sciences of the USA (PNAS), Vol. 109, No. 31, 12326-12331. Retrieved from: http://www.pnas.org/content/109/31/12326.abstract.

NBS. (2008). Seychelles in Figures 2008. Seychelles: Author.

NBS. (2009). Seychelles in Figures 2009. Seychelles: Author.

NBS. (2010). Seychelles in Figures 2010. Seychelles: Author.

NBS. (2011). Seychelles in Figures 2011. Seychelles: Author.

NBS. (2012). Seychelles in Figures 2012. Seychelles: Author.

NBS. (2013). Seychelles in Figures 2013. Seychelles: Author.

NBS. (2014). Seychelles in Figures 2014. Seychelles: Author.

NBS. (2015). Seychelles in Figures 2015. Seychelles: Author.

NBS. (2015). Statistical Abstract 2014, 2015 Edition. Victoria, Seychelles: National Bureau of Statistics.

NORPLAN. (1983). Seychelles' Fisheries Feasibility Study. London: Author.

Porter, M. E. (1990). The competitive advantage of nations. New York: The Free Press. https://doi.org/10.1007/978-1-349-11336-1

Seychelles Nation. (1987). Seychelles 4th biggest consumer of fish. Seychelles Nation. 
SFA. (2006). Annual Report 2006. Seychelles: Author.

SFA. (2007). Annual Report 2007. Seychelles: Author.

SFA. (2008). Annual Report 2008. Seychelles: Author.

SFA. (2009). Annual Report 2009. Seychelles: Author.

SFA. (2010). Annual Report 2010. Seychelles: Author.

SFA. (2011). Annual Report 2011. Seychelles: Author.

SFA. (2012). Annual Report 2012. Seychelles: Author.

Simatupang, T. M. (2007). A Taxonomy of Supply Chain Collaboration. Jurnal Manajmen Teknologi, Vol 6, No. 2, 179-203. Retrieved from: http://journal.sbm.itb.ac.id/index.php/mantek/article/viewFile/66/57.

Van der Elst, R., Everett, B., Jiddawi, N., Mwatha, G., Afonso, S. P., \& Boulle, D. (2004). Fish, fishers and fisheries of the Western Indian Ocean: their diversity and status. A preliminary assessment. Philosophical Transactions of the Royal Society, 323, 263-284.

Van Dijk, M. P., \& Trienekens, J. (2012). Global Value Chains - An overview of the issues and concepts. In M. P. Van Dijk, \& J. Trienekens, Global Value Chains: Linking local producers from developing countries to international markets (pp. 9-30). Amsterdam: Amsterdam University Press.

Van Hoof, L., \& Salz, P. (2001). Applying CPUE as management tool. Paper presented at the XIII Conference of the EAFE 18-20 April, 2001. Salerno: EAFE. Retrieved from: http://www.eafe-fish.org/conferences/salerno/papers/paper37_lucvanhoof.doc.

\section{Copyrights}

Copyright for this article is retained by the author(s), with first publication rights granted to the journal.

This is an open-access article distributed under the terms and conditions of the Creative Commons Attribution license (http://creativecommons.org/licenses/by/4.0/). 